\title{
A Survey on the Implementation of Musculoskeletal Disorders Prevention Program in Shipbuilding Industry
}

\author{
Day Sung Kim \\ Occupational Safety and Health Research Institute, KOSHA, Incheon, 403-711
}

\begin{abstract}
Objective: In 2010, the rate of injuries and illnesses in the shipbuilding industry was 1.20, about 1.74 times higher than the average of overall industries(0.69). Musculoskeletal disorders(MSDs) became a major problem since 2000 in shipbuilding industry. The purpose of this study was to provide efficient implementation management through evaluating the economic effectiveness of the Musculoskeletal Disorders Prevention Program(MDPP). Successfully implementing the MDPP in the workplace may decrease the risk of MSDs and therefore reduce MSDs related costs. Methods: Occupational accident index (frequency rate, severity rate, and frequency severity indicator), estimated direct costs, and total occupational accident occurrence rate were provided by analysis of MSDs, statistical analysis of MDPP decreed companies, and data analysis of implementation. Results: The study shows the number of MSDs for MDPP decreed companies decreased $76.2 \%$ from 2,319 in 2004 to 551 in 2008. Above all, the number of MSDs decreased 78.7\% in Shipbuilding industries. Forty companies (85.1\%) showed a decreasing tendency and $27.7 \%$ of those had an $\mathrm{R}^{2}>0.7$. Similar results were found in severity rate and frequency severity indicator. From these results, it appears there are a number of advantages in implementing the MDPP. Conclusion: MDPP effectiveness was demonstrated by analysing implementation and occupational accident index. A more effective and efficient implementation would take into account business sector, size, policy, and organization of the company.
\end{abstract}

Keywords: Musculoskeletal disorders, Prevention program, Ergonomics program, Shipbuilding industry

\section{Introduction}

산업화, 자동화로 인해 부자연스런 자세, 반복작업, 과도 한 힘의 사용 등으로 인한 근골격계질환(Musculoskeletal Disorders, MSDs) 의 발생이 지속적으로 늘어나고 있으며, 이러한 근골격계질환의 발생은 결국 생산관련 비용의 발생, 산재보상비 지출 등으로 인한 경제적-사회적 문제를 야기 하고 있다. 근골격계질환은 1996년 이후 꾸준히 증가하여 2004년에 총 4,112건으로 업무상질병의 $44.8 \%$ (전체 산업 재해의 $4.6 \%$ )를 점유한 데 이어 2008년에는 69.2\%(6,733 건, 전체 재해의 $7.0 \%$ )로 5 년 동안 $63.7 \%$ 가 증가한 것으 로 나타났다(Ministry of Employment and Labor, 2009).
특히 1,000 인 이상의 대기업을 중심으로 근골격계질환이 급증하여 노·사간의 갈등과 사회적 문제가 되었다. 또한, Korea Workers' Compensation and Welfare Service (2009) 에 의하면, 근골격계질환으로 인한 요양비 등 직접보 상비의 경우에는 2000년 당시 59억 원이었던 것이, 2008년 에는 1,556 억 원으로 약 25.4 배가 증가한 것으로 나타나 간 접비를 추가적으로 고려한다면 근골격계질환으로 인한 국가 적 · 사회적 비용이 상당함을 알 수 있다.

무엇보다, 근골격계질환의 유해요인을 작업관련 요인뿐 아 니라 개인적·사회적인 매개요인들이 더 큰 역할을 한다는 연구들도 보고되고 있어 그 심각성은 더 크다고 할 수 있다. 개인적·사회적 요인들은 개인질병, 작업습관이나 기업문화 등이 대표적인 원인이라 할 수 있는데, 유해요인을 포함한 
특정 작업을 단순하게 개선만으로 이러한 근본적인 문제를 해결하는데 한계가 있기 때문에 전사적인 접근을 통해 근골 격계질환이 발생하지 않도록 사전에 예방하는 것이 필수적 이다. 따라서 외국에서는 근골격계질환 관련 비용이 국가적 으로 많은 손실을 초래하고, 국민의 삶의 질 저하에 영향을 미치자 1990년대 초반부터 미국 등을 비롯하여 구미 선진 국에서는 근골격계질환 관련 법률을 제정하기 시작하였다. 이는 인간공학적 접근을 통한 해결방법으로써 근골격계질환 의 원인을 경영층부터 작업자 개개인들까지 참여하는 종합적 이고 체계적인 시스템으로 관리하는 것이 바람직하다는 여 러 연구들을 기반으로 인간공학적인 측면이 다양한 방법으 로 고려되어야 함을 강조하고 있다.

우리나라도 2003년 산업안전보건기준에 관한 규칙에 연 간 10 인 이상 근골격계질환이 발생하는 경우에는 「근골격계 질환 예방관리프로그램」을 법적으로 작성 - 시행토록 규정하 고 있으나 예방관리프로그램 운영 자체가 초기 도입단계에 있고, 적용하고 있는 사업장도 그리 많지 않아 운영실태에 관한 연구가 부족한 실정이다. 무엇보다, 근골격계질환의 근 본적인 예방을 위해 몇몇 기업에서 운영하고 있는 예방관리 프로그램에 대한 효과분석을 통해 다양한 업종의 기업에 적 용할 수 있도록 활성화하는 것이 필요하다.

우리나라의 근골격계질환 예방관리프로그램은 외국에서는 「인간공학프로그램(Ergonomics Program)」으로 불리고 있 으며(OSHA, 1993; Worksafe BC, 2009), 주로 인간공학적 작업장 평가와 작업환경개선, 교육 및 훈련 등을 통한 일상 적인 관리를 지속적 - 체계적으로 수행함으로써 사전예방하 는 접근방법으로 미국 산업안전보건청 (Occupational Safety and Health Administration; OSHA) 의 Ergonomic Program Management Guideline for Meatpacking Plants(OSHA, 1993)이 가장 대표적이다. 동 보고서는 사업장에서 이용 가 능한 근골격계질환 예방을 위한 프로그램으로써 경영층이 참여하는 것을 전제로 하여 작업장 및 작업조건에 대한 인간 공학적 분석, 유해요인의 개선, 의학적 조치, 교육 및 훈련 등 네 가지 사항을 제시하고 있다. 미국 정부의 적극적인 홍 보와 대기업의 충실한 참여로 비교적 잘 운영되고 있으며, 몇몇 보고서에 따르면, 인간공학프로그램으로 인해 근골격계 질환자에 대한 비용이 감소되었고, 생산성 향상과 작업자 사 기진작 등을 유도함으로써 작업자의 이직률과 결근률을 감 소시키는 것으로 보고하고 있다.

특히, 조선업종은 자동차업종과 더불어 근골격계질환자가 다발하는 대표적인 업종임에도 불구하고 기존에 소개되고 있는 인간공학프로그램은 자동차 및 IT 계열의 기업에서 운 영하고 있는 것이 대부분이다. 이는 외국의 산업규모가 자동 차 및 IT 계열에 집중되어 있기 때문이다. 우리나라의 조선 해양산업은 2000년대 초반까지 세계 조선해양산업의 1 위를
고수하였고, 2008년 이후 중국의 부상으로 주춤한 상황이기 는 하나 2011년에는 다시 수주량 세계 1위를 기록하고 있 다(Ministry of Knowledge Economy, 2011). 이러한 조 선업종에서 발생한 근골격계질환의 발생비율은 2004년에 $14.8 \%$ 이며, 조선업종에서 발생한 직업병의 $61.5 \%$ 를 점유 하고 있다(Pyo and Jeong, 2007). 조선업종에 대한 근골 격계질환 예방을 위한 연구는 Guidelines for Shipyards (OSHA, 2008)에서 간단한 개선사례를 소개하고 있을 뿐 대부분이 국내 연구에 국한되어 있으며 그 건수도 미비한 실 정이다. Oh et al.(2005)의 연구에서는 2004년 한 해 동안 인간공학프로그램을 운영한 결과, 생산성 $5.2 \%$ 향상, 사고 성재해 $3 \%$ 감소, 비사고성재해 $53 \%$ 감소한 것으로 보고 하고 있으며, Kim and Chang(2006)은 일개 조선업종에서 3 년간 인간공학프로그램을 운영한 후 근골격계질환이 최대 $30 \%$ 감소한 것으로 보고하였다. Pyo and Jeong (2007)의 연구에서도 산재부담금 $22 \%$ 감소, 근골격계질환자 41.5 $71.1 \%$ 감소한 것으로 보고하였다. 다만, 이러한 연구들은 대부분 일개의 사업장에서 운영한 사례로써 조선업 전반에 서 활용하는데 한계가 있다.

따라서, 본 연구에서는 조선업종을 포함한 법적으로 근골 격계질환 예방관리프로그램을 운영하고 있는 사업장의 산업 재해지수의 변화를 분석함으로써 예방활동의 효과를 알아보 고자 한다. 이러한 결과는 자율적으로 예방관리프로그램을 운영하고자 하는 사업장에 많은 도움이 될 것으로 기대된다.

\section{Method}

SafeComputingTips.com(2009)에서는 사업장내에서 운 영하고 있는 인간공학프로그램에 대한 평가가 필요한 3 가지 이유를 제시하고 있다. 첫 번째로 사업장의 인간공학프로그 램은 감당할 수 있는 비용에 비해 요구하는 결과를 얻지 못 할 수 있으며, 두 번째, 사업장의 인간공학프로그램이 효과 적이고 효율적이지만, 개선되어야만 한다는 것이다. 마지막 으로, OSHA의 인간공학프로그램 초안에서 매 3년마다 인 간공학프로그램에 대한 평가를 요구하고 있기 때문에 인간 공학프로그램을 정기적으로 평가해야 한다고 보고하고 있다. Kaizer A.A.S et al. (2009)는 인간공학프로그램을 평가하는 방법은 크기 Macro적인 측면과 Micro적인 측면을 고려해야 하는데, Macro적인 방법은 조직적인 시스템적 측면 고려, 생 산성 지표, 산업재해 분석, 산업재해 관련 비용효과분석 등 을 통해 기업 전반에 미치는 영향을 평가하는 것이며, Micro 적인 방법은 인체측정자료 분석, 생체역학적 분석, 작업의 부하분석을 통해 소극적인 개선 전후를 비교하는 방법이다. 
다만, 예방관리프로그램의 효과를 평가하는 방법에 대해서는 다양한 의견과 사업장내의 문화 등이 상당히 큰 영향을 미치 는 것으로 보고되고 있다.

따라서, 본 연구에서는 산업안전보건기준에 관한 규칙에 의거하여 법적으로 근골격계질환 예방관리프로그램을 작성 - 시행해야 하는 47 개 사업장(특히 조선업종)을 대상으로 예방관리프로그램 운영에 대한 설문조사와 근골격계질환 노 출실태를 분석하여 운영하고 있는 예방관리프로그램에 대한 효과를 파악하고자 하였다. USACHPPM(2004)에서는 개별 사업장에 대한 근골격계질환 노출실태를 통한 예방관리프로 그램의 효과를 평가하는 척도로써 산업재해지수(발생건수, 빈도율, 근로손실일수 및 강도율 등), 유해요인 노출특성의 변화와 작업자의 만족도 변화도 중요한 평가척도로 제시하 고 있다. 다만, 본 연구에서는 개별사업장이 아닌 47 개 사업 장에서 수행하고 있는 예방관리프로그램을 종합적으로 평가 해야 하기 때문에 작업자의 만족도, 결근율, 생산성 및 매출 액 등 지나치게 사업장 내부정보이거나 사업자의 특성이 반 영된 것은 가능하면 배제하고자 하였다. 따라서, 고용노동부 에서 발표한 2004 2008년(5년간)의 근골격계질환에 대한 현황분석을 통해 47 개 사업장에 대한 근골격계질환의 노출 실태를 분석하였고, 특히 빈도율, 강도율, 종합재해지수를 이 용하여 5 년간의 예방활동에 대한 효과를 살펴보았다.

\section{Results}

\subsection{Analysis of exposure prevalence}

근골격계질환 예방관리프로그램 대상사업장은 2009년도 시점에서 사고성요통 및 진동장해로 인한 근골격계질환을 제외하고 2004 2008년까지의 대상사업장을 재선정한 결 과, 법적으로 예방관리프로그램을 운영해야 할 사업장은 전 체 50 개소이며, 이중에서 3 개소가 폐업하여 총 47 개소를 최 종 대상으로 선정하였다. Figure 1은 예방관리프로그램 대상 사업장의 규모별 사업장 비율을 나타낸 것으로 2,000인 이 상 $(47 \%)>1,000 \sim 1,999$ 인 $(19 \%)>500$ 999인 $(17 \%)>$ 500 인 이하 $(17 \%)$ 순으로 규모가 클수록 높은 비율을 나타 내고 있으며, 특히, 2,000 인 이상의 대기업이 전체의 절반이 상을 점유하는 것으로 나타났다. 이중 조선업종은 6 개소로써 모두 2,000인 이상의 대기업에 포함되어 있다. Figure 2은 업종별 특성으로써, 자동차부품제조업이 $34 \%$, 자동차제조업 이 $25 \%$, 조선업종이 $13 \%$ 로 나타나 전체 근골격계질환발생 업종 특성과는 차이가 나는 것을 알 수 있다. 지역별로는 경 남 $(18 \%)>$ 충남 $(15 \%)>$ 전북 $(11 \%)=$ 경기남부 $(11 \%)$ 순 으로 높게 나타나고 있다. 이는 자동차제조 및 부품제조업,
조선업종이 소재하고 있는 지역에서 높은 비율을 보이는 것 으로 나타났다.

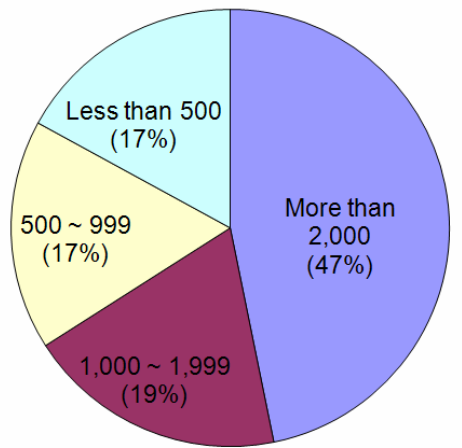

Figure 1. The ratio by workplaces sizes in MDPP decreed companies

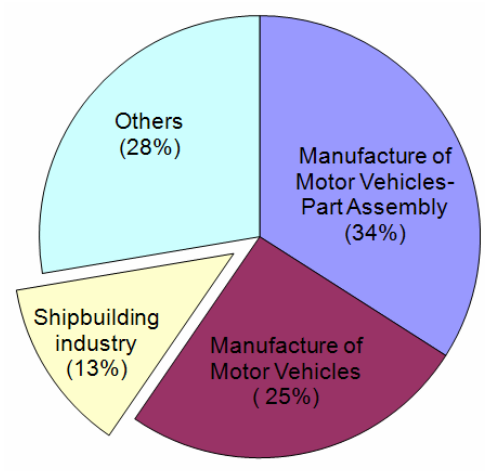

Figure 2. The ratio by industry types in MDPP decreed companies

예방관리프로그램 대상사업장의 근골격계질환자가 전체 근골격계질환자 중 점유하고 있는 비율을 살펴보면(Table 1), 2004년에 56.4\%였던 것이 2008년에는 $16.5 \%$ 로 나타 나 다발사업장에 대한 점유비율이 큰 폭으로 감소한 것을 알 수 있다. 또한, 전체 산업재해는 2004년에 5,833건이었던 것이 2008 년에는 2,636 건으로 $54.8 \%$ 감소한 반면에 근골 격계질환자수는 2004년에 비해 2008년에는 $76.2 \%$ 감소한 것으로 나타났다. 이는 예방관리프로그램 대상사업장에서 근 골격계질환에 대한 감소율이 상대적으로 높은 것을 알 수 있 다. 또한, 우리나라 전체의 근골격계질환 발생건수와 비교해 보면, 2004년에 4,112건이었던 것이 2008년에는 3,332건 으로 약 $19 \%$ 감소한 것에 비해서는 월등히 많은 감소비율 을 나타내는 것을 알 수 있다. 특히 조선업종의 근골격계질 환 발생건수는 해당 기간 동안에서 평균 $28.2 \%$ 를 점유하는 것으로 나타났다. 또한 2004년에 비해 2008년에는 $78.7 \%$ 로 예방관리프로그램 운영 사업장보다 높은 비율로 감소한 것으로 나타났다. 
Table 1. Prevalence of Musculoskeletal Disorders(MSDs)

\begin{tabular}{l|c|c|c|c|c}
\hline & 2004 & 2005 & 2006 & 2007 & 2008 \\
\hline \begin{tabular}{l} 
Total cases of MSDs \\
\hline $\begin{array}{l}\text { Cases of MSDs in MDPP } \\
\text { decreed companies } \\
\text { (47 companies) }\end{array}$
\end{tabular} & 4,112 & 2,901 & 2,621 & 1,954 & 3,332 \\
\hline \begin{tabular}{l} 
Rate of MSDs in MDPP* (\%) \\
\hline $\begin{array}{l}\text { Cases of MSDs in } \\
\text { shipbuilding industry }\end{array}$
\end{tabular} & 56.4 & 46.357 & 883 & 550 & 551 \\
\hline Rate of MSDs in SI** (\%) & 25.5 & 31.5 & 27.4 & 33.6 & 22.9 \\
\hline
\end{tabular}

*Rate of MSDs in MDPP $=$ Cases of MSDs in MDPP decreed companies/Total Cases of MSDs

${ }^{* *}$ Rate of MSDs in SI = Cases of MSDs in Shipbuilding industry/Cases of MSDs in MDPP

\subsection{Results of survey}

예방관리프로그램 운영실태를 파악하기 위해 47 개 사업장 을 대상으로 설문조사를 실시하였는데, 총 46사업장(97.9\%) 이 응답하였다.

설문조사결과를 구체적으로 살펴보면, 근골격계질환 예 방업무를 전담하고 있는 분야에 대한 조사결과, 산업안전 $(26.5 \%)>$ 간호사 $(20.4 \%)>$ 인간공학 $(19.4 \%)>$ 산업위생 (18.4\%) 순으로 나타났으며, 예방관리프로그램에 대한 인지 도를 조사한 결과, $89.1 \%$ 정도가 잘 알고 있는 것으로 조사 되었다. 예방관리프로그램을 도입한 시기에 대한 조사결과, 2005년(32.6\%) > 2004년(30.4\%) > 2003년(23.9\%) 순 으로 높게 나타났다. 이는 산업안전보건기준에 관한 규칙이 2003. 7. 12일 이후에 시행되었기 때문에 2003년도에 시행 한 사업장이 상대적으로 적으며, 예방관리프로그램을 도입하 여 노·사 협의 등의 과정을 거쳐 운영하기 시작한 시기가 2004년 2005년에 집중된 것으로 추정된다.

예방관리프로그램 도입방법은 대학기관 등의 외부컨설팅 기관을 통해서 작성한 경우가 $49 \%$ 로 가장 높았고, 내부인 력 $(44.9 \%)>$ 벤치마킹 $(4.1 \%)$ 순으로 나타났다. 도입동기로 는 노동조합의 요구(54.3\%)와 정부기관에서 권장(41.3\%) 한 것이 안전보건부서 자발적 도입, 사업주 권장 보다 높은 것으로 나타났다. 도입 시 노동조합과의 합의 $(69.6 \%)>$ 노 동조합과의 협의(28.3\%) 순으로 $97.8 \%$ 가 노동조합과의 협 조를 통해 예방관리프로그램 도입한 것으로 조사되었다.

예방관리프로그램 도입 후 운영상황 및 효과(성과)에 대 한 분석결과, 도입 후 $69.6 \%$ 가 운영상황이 비교적 잘 운영 되고 있는 것으로 응답하였는데, 매우 잘 운영되고 있다는 응답도 전체 $26.1 \%$ 로 나타났다. 운영상황이 좋은 사업장 일 수록 효과도 큰 것으로 나타났다. 이러한 결과는 예방관리프 로그램을 도입하고자 하는 사업장에 시사하는 바가 크다고
할 수 있다. 도입에 따른 안전보건 성과에 대한 조사결과, 안 전보건관리체계가 확립된 것을 가장 높은 성과로 지적하였 고, 사내 계측간 의사소통과 근골격계질환의 감소와 안전보 건 투자의 확대를 그 다음으로 꼽았다. 다만, 생산성이나 매 출 등이 향상되었다는 응답은 상대적으로 적은 것으로 응답 하였다. 또한, 중간관리자 및 현장관리자의 의식이 향상된 것으로 응답하였다.

예방관리프로그램을 운영하는데 가장 큰 장해요인은 전문 인력의 부족하기 때문에 예방활동이 성공하기 위해서는 무 엇보다 전문인력을 양성하는 것이 필요한 시점이라 할 수 있다. 예방관리프로그램을 활성화하기 위한 방안으로는 인간 공학 분야 전문인력 양성, 관리감독 면제, 대상범위 조정 및 졸업기준 신설 등이 필요한 것으로 지적되었다. 무엇보다, 근골격계질환 예방관리프로그램의 운영효과를 극대화 하기 위해서는 예방관리프로그램에 대한 정기적인 관리 및 심사 제도의 도입이 절실히 필요하다 $(41.3 \%)$ 고 응답하였다.

\subsection{Analysis Results of the operation}

Figure 3은 근골격계질환 예방관리프로그램을 운영한 47 개소에 대한 근골격계질환 발생실태 및 산업재해지수(빈도 율, 강도율, 종합재해지수)를 이용하여 근골격계질환의 변화 추이를 분석한 결과를 나타낸 것이다. 대상사업장들의 근골 격계질환 발생실태를 살펴본 결과, 2004년 2,319건이였던 것이 2008 년에는 551 건으로 약 $76.2 \%$ 가 감소하였고, 평균 빈도율의 경우, 가장 높은 2004년(6.73) 이후에 지속적으 로 감소하여 2008 년에는 1.97 로 약 $70.7 \%$ 감소하였다. 또 한, 평균 강도율은 $65.1 \%$, 평균 종합재해지수는 $70 \%$ 가 감 소한 것으로 나타났다. 이는 OSHA (2000)의 평균 감소율 인 $73 \%$ 와 거의 유사한 결과를 보이고 있다. Figure 4는 조 선업종의 변화추이를 나타낸 것으로 평균 빈도율은 2004년 에 비해 2008년에는 약 $48.1 \%$ 감소한 것으로 나타났다. 또 한 조선업종의 평균 강도율도 $48.6 \%$, 평균 종합재해지수는 $48.4 \%$ 로 나타났다. 이는 예방관리프로그램을 운영하는 47 개 사업장의 결과(Figure 3)와 비교해 비교적 낮은 비율로 감소한 것을 알 수 있다.

이러한 산업재해지수는 특정사업장의 급격한 감소나 증가 에 얼마나 영향을 받고 있는지 여부를 판단하기 어렵기 때문 에 정확한 분석을 위해 개별사업장에 대한 분석이 필요하다. 따라서, 개별 대상사업장별 산업재해지수의 변화형태를 결정 계수 $\left(\mathrm{R}^{2}\right)$ 를 이용하여 감소 또는 증가 추세에 따라 결정계수 값이 0.3 미만, 0.3 0.7, 0.7 이상으로 구분하여 나타내었다. 일반적으로 결정계수는 추세의 형태를 설명하는 지표로 사 용되고 있는데, 감소추세에 있고 결정계수값이 0.7 이상이면 "상당히 큰 폭으로 감소"하고 있음을 보여주는 것이고, 반대 


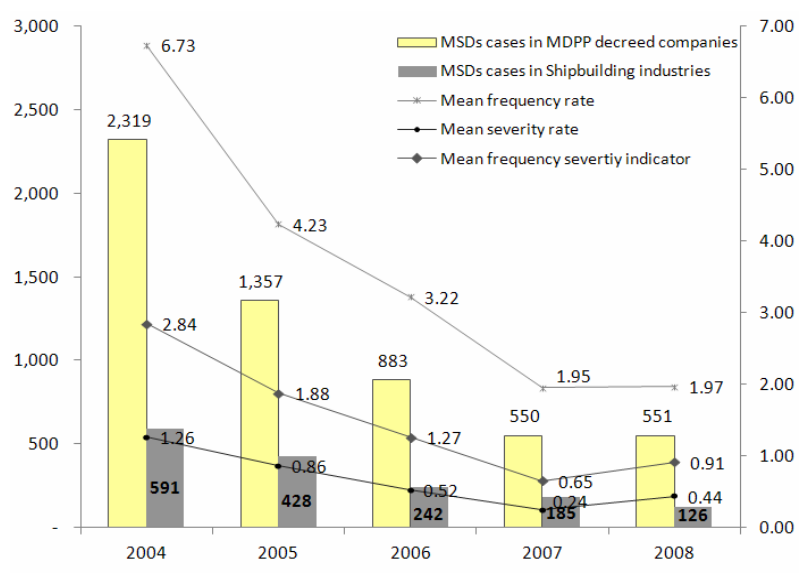

Figure 3. MSDs related accident index in MDPP companies

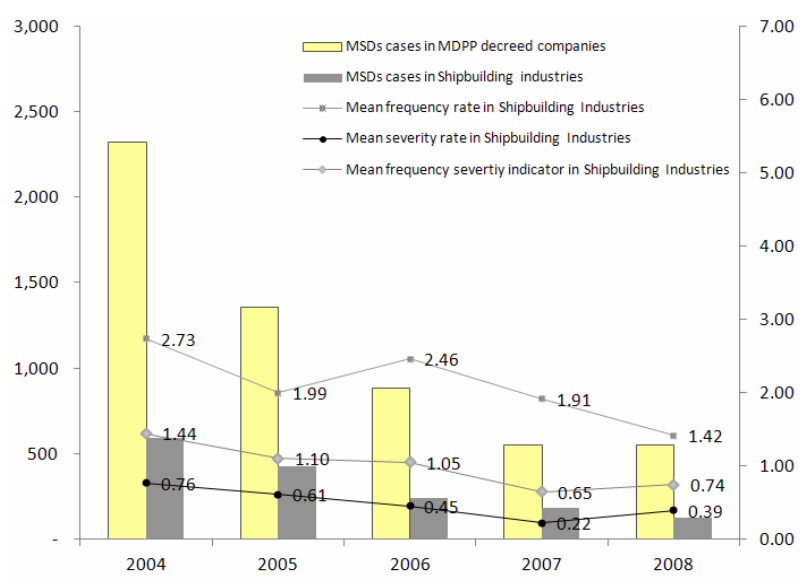

Figure 4. MSDs related accident index in shipbuilding industries

Table 2. Occupational accident index for individual companies

\begin{tabular}{c|c|c|c|c}
\hline \multirow{2}{*}{ Tendency } & $\begin{array}{c}\text { Coefficient of } \\
\text { determination }\left(\mathrm{R}^{2}\right)\end{array}$ & $\begin{array}{c}\text { Frequency } \\
\text { rate }\end{array}$ & $\begin{array}{c}\text { Severity } \\
\text { rate }\end{array}$ & $\begin{array}{c}\text { Frequency } \\
\text { severity } \\
\text { indicator }\end{array}$ \\
\hline \multirow{3}{*}{$\begin{array}{c}\text { Decreasing } \\
\text { tendency }\end{array}$} & Less than 0.3 & $11(23.4 \%)$ & $8(17.0 \%)$ & $8(17.0 \%)$ \\
\cline { 2 - 5 } & $0.3 \sim 0.7$ & $16(34.0 \%)$ & $18(38.3 \%)$ & $17(36.2 \%)$ \\
\cline { 2 - 5 } & More than 0.7 & $13(27.7 \%)$ & $11(23.4 \%)$ & $14(29.8 \%)$ \\
\hline \multirow{2}{*}{$\begin{array}{c}\text { Increasing } \\
\text { tendency }\end{array}$} & Less than 0.3 & $3(6.4 \%)$ & $6(12.8 \%)$ & $4(8.5 \%)$ \\
\cline { 2 - 5 } & $0.3 \sim 0.7$ & $3(6.4 \%)$ & $3(6.4 \%)$ & $3(6.4 \%)$ \\
\cline { 2 - 5 } & More than 0.7 & $1(2.1 \%)$ & $1(2.1 \%)$ & $1(2.1 \%)$ \\
\hline
\end{tabular}

로, 증가추세에 있으면서 결정계수값이 0.3 미만이면 "어느 정도 증가"하는 추세를 보이는 것을 의미한다. 이러한 기준 에 따라 개별사업장의 산업재해지수에 따라 근골격계질환의 변화형태를 살펴본 결과(Table 2), 빈도율의 경우, 47 개 사 업장 중에서 총 40 개소(85.1\%)가 감소추세를 보이고 있으
며, 그 중에서 결정계수가 0.7 이상인 비율이 전체 13 개소 (27.7\%)를 점유하고 있는 것으로 조사되었다. 반면 증가추 세를 보이는 사업장도 전체 7 개소(14.9\%) 뿐인 것으로 나 타났으며, 급격하게 증가하는 0.7 이상도 1 개소로 분석되었 다. 강도율과 종합재해지수에 대한 분석결과도 Table 2와 같이 빈도율과 비슷한 수준을 보이는 것으로 나타났다.

\section{Conclusion}

본 연구는 근골격계질환 예방관리프로그램을 법적으로 작성 · 시행하고 있는 47 개 사업장을 대상으로 예방관리프로 그램 운영에 대한 설문조사를 실시하였고, 근골격계질환 발 생실태 및 산업재해지수를 이용하여 근골격계질환에 대한 노출평가를 통해 효과분석을 실시하였다.

예방관리프로그램 대상사업장의 근골격계질환자가 전체 근골격계질환자 중 점유비율을 살펴보면, 2004년에 $56.4 \%$ 였던 것이 2008년에는 $16.5 \%$ 로 나타나 큰 폭으로 감소하 였다. 설문조사결과, 예방관리프로그램 도입시기는 $63 \%$ 의 사업장이 2004 2005년으로 응답하였고, 도입방법은 대학 기관 등의 외부컨설팅 기관(49\%)이나 내부인력(44.9\%)을 이용하였고, 운영상황은 잘 운영되고 있다는 비율이 $95.7 \%$ 로 매우 높았다. 다만, 예방관리프로그램을 도입하여 유지하 는데 장해요인으로 전문인력의 부족을 꼽을 정도로 해당 분 야 즉, 인간공학 분야의 전문인력에 대한 양성과 심사제도 도입이 절실히 필요한 것으로 조사되었다. 산업재해지수(빈 도율, 강도율 및 종합재해지수)에 대한 분석결과, 2004년 2,319 건이였던 것이 2008 년에는 551 건으로 약 $76.2 \%$ 가 감소하였다. 특히, 조선업종의 경우에는 $78.7 \%$ 가 감소하였 다. 이러한 결과들을 종합하여 볼 때, 근골격계질환 예방관 리프로그램을 운영할 경우에는 다양한 효과를 기대할 수 있 는 것으로 나타났다.

인텔(Intel)은 인간공학프로그램 도입 후 1994 1998까 지 근골격계질환의 비율이 $72 \%$ 감소되었고, 직 · 간접비용은 약 1 억불 이상 절약된 것으로 보고되고 있다(Intel, 1999). Johns Hopkins병원과 대학은 1992년에 작업관련 근골격계 질환의 발생을 줄이기 위하여 대략 2 만명의 작업자에게 적 용되는 포괄적인 인간공학프로그램을 시작했다. 1992년에 실행한 이후 7년간, 1992년에 1천명당 6.5명에서 1998년 에 1 천명당 1.3 명으로 $80 \%$ 의 상지부위 근골격계질환의 비 율이 유효하게 감소한 것으로 보고하고 있다(Bernacki et al., 1999). 또한, Joseph (2003)는 Ford 자동차에 대한 연구에 서 인간공학프로그램의 효과와 비용을 측정하는 것은 매우 어려운 것이었지만, 인간공학프로그램을 통해 $300 \%$ 이상의 
비용절감효과, $72 \%$ 의 결근율 감소, 질환 발생건수도 상지부 위가 57 86\%, 허리가 56\% 정도 감소하였다고 보고하였다. 다만, 이러한 운영효과에도 불구하고 보다 효율적으로 정착 하기 위해서는 전사적, 시스템적인 접근이 필요하며 작업자 의 자율적 참여가 요구되며, 예방관리프로그램을 운영하기 위한 인간공학 분야의 전문인력의 양성과 확보가 절실히 요 구되며, 제도적인 측면에서의 다각적인 검토와 지원이 필요 하다고 지적하고 있다.

따라서, 사업장내에서 근골격계질환 예방관리프로그램을 효율적으로 운영하기 위해서는 예방관리프로그램의 기본적 인 틀을 활용하여 회사의 업종 및 규모, 정책, 조직 등에 따 라 매우 다양하게 접근할 수 있어야 하며, 이러한 접근을 통 해 사업장내에서 자체적으로 만들어가는 것이 무엇보다 중 요하다. 또한 단기간의 활동으로 완벽하게 성공하기에는 매 우 어려운 사안이기 때문에 장기적인 계획에 의해 전사적이 고 일상적인 체계를 바탕으로 추진해 나가는 것이 반드시 필 요하다. 아울러 예방관리프로그램 운영상황을 정기적으로 평 가하여 부족한 항목에 대해서는 피드백을 통해 효율성을 높 여 지속적으로 추진할 수 있도록 해야 한다.

\section{References}

Bernacki, E. J., Guidera, J. A, Schaefer, J. A., Lavin, R. A. and Tsai, S. P., An ergonomics program designed to reduce the incidence of upper extremity work related musculoskeletal disorders, J. Occup. Environ. Med., 1999.

Intel Corporation, Intel Corporation wins 1999 outstanding office ergonomics award, Center for office technology, 1999.

Joseph, B. S., Corporate ergonomics programme at Ford Motor Company, Applied Ergonomics 34, 23-28, 2003.

Kaizer, A. A. S, Marchal, M. A. and Kaizer, R. T. D., "Applicability of ergonomic risk management to measure the results of performance and quality of life at work", 17th world congress on Ergonomics, 2009.

Kim, Y. C. and Chang, S. R., The Effect and Management of the Ergonomics Program for the Prevention of WMSDs in a Shipbuilding Industry, Journal of the KOSOS, 21(6), 101-105, 2006.

Korea Workers' Compensation and Welfare Service, Annual MSDs compensation insurance premium(2004 2008), http://www. kcomwel.or.kr/, 2009.

Ministry of Employment and Labor, Statistics on Occupational injuries and diseases in 2004 2008, Ministry of Employment and Labor, 2009.

Ministry of Knowledge Economy, Shipbuilding industry of Korea, the world's Number 1 at 1 / 4 Quarter in 2011, www.mke.go.kr, 2011.
Occupational Health \& Safety Administration(OSHA), Ergonomics Program Guidelines for Meatpacking Plants, U.S. Department of Labor, 1993.

Occupational Safety and Health Administration(OSHA), Ergonomics Program: Final Rule, U.S. Department of Labor, 2000.

Occupational Safety and Health Administration(OSHA), Guidelines for Shipyards - Ergonomics for the Prevention of Musculoskeletal Disorders, U.S. Department of Labor, 2008.

Occupational Safety and Health Administration(OSHA), Preliminary economic analysis and initial regulatory flexibility analysis for the occupational safety and health administration's proposed ergonomics program standard, U.S. Department of Labor, 1996.

Oh, S. Y., Pyo, Y., Yu, Y. S., Jeong, B. Y., Lee, D. K. and Nah K., "An Implementation Case of Ergonomics Program at a Shipbuilding industry", Proceedings of 2005 Spring Conference of Ergonomics Society of Korea, 2005.

Pyo, Y. and Jeong, B. Y., An Implementation Case of Ergonomics Program at a Shipbuilding Company, Journal of the Ergonomics Society of Korea, 26(3), 45-52, 2007.

SafeComputingTips.com, Workplace Ergonomics Program-Evaluation, www.safecomputingtips,com, 2009.

US Army Center for Health Promotion and Preventive Medicine (USACHPPM), Ergonomics program evaluation checklist, Retrieved October 10, 2004.

Washington State Department of Labor and Industries, Cost-Benefit Analysis of the Ergonomics Standard, Washington State Department of Labor and Industries, 2000.

WorkSafe BC, Ergonomics Program Template, http://www.worksafebc.com/, 2009.

\section{Author listings}

Day Sung Kim: ergoman@kosha.net

Highest degree: $\mathrm{PhD}$, Department of Industrial \& Management Engineering, University of Incheon

Position title: Researcher, Occupational Safety \& Health Research Institute, KOSHA

Areas of interest: Industrial Ergonomics, Musculoskeletal Disorders

Date Received : 2011-12-24

Date Revised :2012-01-10

Date Accepted : 2012-01-10 